\title{
Invasive cutaneous Neoscytalidium infections in renal transplant recipients: a series of five cases
}

Simon Garinet ${ }^{1}$, Jérôme Tourret ${ }^{2,3}$, Stéphane Barete ${ }^{3,4}$, Nadia Arzouk $^{2}$, Isabelle Meyer ${ }^{1}$, Camille Frances ${ }^{3,4}$, Annick Datry ${ }^{1,3}$, Dominique Mazier ${ }^{1,3,5}$, Benoit Barrou ${ }^{2,3}$ and Arnaud Fekkar ${ }^{1,3,5^{*}}$

\begin{abstract}
Background: Neoscytalidium species (formerly Scytalidium species) are black fungi that usually cause cutaneous infections mimicking dermatophytes lesions. Very few publications have reported invasive or disseminated infections.

Case presentation: In this paper, we report the clinical presentations, treatments and outcomes of five cases of invasive Neoscytalidium infections with cutaneous involvement, including two cases with disseminated infection, in five renal transplant recipients. To our knowledge, this is the first report of a series—albeit small —of renal transplant patients in whom this infection was identified. All cases occurred in a single hospital in Paris, France, between 2001 and 2011. Patients all originate from tropical area.

Conclusion: Treatments of Neoscytalidium infection varied greatly, underlining the lack of a recommendation for a standardized treatment. All patients were cured after long-term antifungal therapy and/or surgical excision. Interestingly, one patient with disseminated infection involving the left elbow, the right leg, the lungs and the nasal septum was cured by medical therapy only without surgery. This may suggest that in contrast to others mycoses (such as mucormycosis), an adequate medical treatment could be sufficient for treating Neoscytalidium. We also point out the difficulties we had in diagnosing two patients with Kaposi's sarcoma because of the similarity of the lesions. Furthermore, our report underlines the need to check for this rare infection in immunocompromised kidney transplant recipients originating from tropical areas.
\end{abstract}

Keywords: Fungal infection, Renal transplant, Solid organ transplant, Immunodepression, Moulds

\section{Background}

Neoscytalidium spp. (formerly Scytalidium) are ascomycetous fungi counted among a large and heterogeneous group of fungi that cause phaeohyphomycosis. One of the particular characteristics of these fungi, known collectively as dematiaceous fungi or black mold, is to produce dark melanized hyphae [1]. They are distributed worldwide in tropical and subtropical regions and are principally known as phytopathogens [1-4]. Thus, they are mainly associated with plants and fruit trees, but can also be isolated from soil $[1,5]$.

\footnotetext{
* Correspondence: arnaud.fekkar@psl.aphp.fr

'AP-HP, Groupe hospitalier La Pitié-Salpêtrière, Service de Parasitologie Mycologie, F-75013 Paris, France

${ }^{3}$ Sorbonne Universités, UPMC Univ Paris 06, F-75005 Paris, France

Full list of author information is available at the end of the article
}

Some however can infect humans via direct contact, sometimes traumatic, with colonized plants or vegetable residues [1]. They usually cause superficial infections such as onychomycosis or dermatomycosis and are considered as "dermatophytes-like" pathogens [1-6]. The two species involved in human infections are Neoscytalidium dimidiatum and its albino variant Neoscytalidium hyalinum, which does not produce melanin [1,7]. $N$. dimidiatum is the synanamorph of Nattrassia mangiferae (formerly Hendersonula toruloidea) that was described for the first time in Egypt in 1933 by Nattrass as a phytopathogen [8]. The first cases in human infection were described in 1970 and consisted of ungual and cutaneous lesions in patients originating from tropical 
areas [9]. The first case of $N$. hyalinum was described a few years later in patients with similar lesions [10].

On rare occasions, Neoscytalidium may be involved in deeper cutaneous and subcutaneous infections, as well as disseminated infections, especially in immunocompromised patients. In this setting, various clinical forms have been described, including central nervous system abscesses, endophthalmitis, sinusitis, osteomyelitis, mycetoma, subcutaneous lesions and disseminated infections $[1,11-21]$.

We report here the clinical presentations, treatments and outcomes of five deep cutaneous infections due to Neoscytalidium spp., two of which involved dissemination, that occurred in five renal transplant recipients in our institution in Paris, France.

\section{Materials and methods}

\section{Definition of the cases}

Proven invasive fungal disease was as defined by the EORTC/MSG Consensus Group [22]. An invasive case was defined as the presence of fungal elements in a specimen obtained by biopsy or needle aspiration from a normally sterile site. Dissemination was defined as the involvement of two or more non-contiguous sites.

\section{Culture}

Cultures for all samples were performed on Sabouraud agar without cycloheximide and supplemented with chloramphenicol and gentamicin. Media were incubated at $25{ }^{\circ} \mathrm{C}$. As Neoscytalidium grows faster than dermatophytes, cultures were positive in 2 to 4 days. Identification was performed with macro/microscopic observation of the culture.

\section{Onychomycosis cases}

All skin and nail samples collected in our laboratory between January 1, 2010 and December 31, 2011 were reviewed to identify the cultures that led to the macro/ microscopic identification of Neoscytalidium spp.

\section{Case presentation (Table 1) \\ Case 1}

The first patient was a 53-year-old male who originated from French Guyana. He had received a kidney transplant in December 2000 for nephroangiosclerosis. At admission (in February 2001), his medications included mycophenolate mofetil $250 \mathrm{mg}$ daily, tacrolimus $3 \mathrm{mg}$ twice daily and prednisone $20 \mathrm{mg}$ daily as immunosuppressant therapy. He was diagnosed as having Kaposi's sarcoma with cutaneous, gastric and gut localizations. During his hospital work-up, a subcutaneous nodule was found on the right leg. A biopsy of the nodule demonstrated inflammation with fungal elements identified via mycological culture as Neoscytalidium spp. This same agent was found concomitantly on a toenail sample. Chest and abdomen CT scans for staging found no internal fungal localizations. The patient's blood cultures were negative. A systemic oral antifungal therapy with itraconazole (400 $\mathrm{mg}$ twice daily) was initiated but 2 months later the leg lesion was still culture-positive. The lesion was thus excised but the surgery proved incomplete and the lesion remained secondarily positive. Thereafter, local treatments with amphotericin Bimpregnated paraffin gauze were added, but again, samples collected 4 months after surgery were still positive for mycelium filaments and culture. The patient was then lost to follow-up for one and a half years. He reappeared in March 2005. Unexpectedly, no active fungal lesion was detected and he was therefore considered as cured of his Neoscytalidium infection.

\section{Case 2}

The second patient was a 64-year-old female born in Ivory Coast. She was admitted for infection as a complication of Kaposi's sarcoma in September 2002. Her medical history included polycystic renal disease that required renal transplantation in 1991, followed by extensive cutaneous Kaposi's sarcoma in 1996. At admission, her medications included cyclosporine $100 \mathrm{mg}$ daily and prednisolone $10 \mathrm{mg}$ daily. During her hospitalization, various mycological examinations were positive: direct examination of left foot, right foot (sole and nail), and right leg lesion samples showed mycelian filaments identified as a $N$. hyalinum in culture. Magnetic resonance imaging of the left foot showed inflammatory and edematous remodeling of tissues, difficultly distinguishable from tumor infiltrations, but no bone lesions were observed. Initially, the treatment included both local and systemic terbinafine but an interaction with cyclosporine led to a fast deterioration of renal function. The systemic treatment was thus discontinued in regard to the risk for renal function and the clinical regression of the lesions. The local terbinafine treatment however was continued. Evolution was favorable with negative mycological cultures 4 months later.

\section{Case 3}

The third patient was a 52-year-old male originating from Mauritania who had received an initial renal transplant in 1991 for polycystic renal disease and underwent a second renal transplantation in 2000. At admission, his medications included mycophenolate mofetil $(750 \mathrm{mg}$ twice daily), tacrolimus (3 $\mathrm{mg}$ daily) and prednisone (10 mg daily). In November 2007, he came back to the hospital for a post-traumatic lesion on the right leg. During the dermatological examination, an infiltrated, pigmented, and painless lesion measuring approximately $1.5 \mathrm{~cm}$ in diameter was found on the anterior face of the 
Table 1 Characteristics of 5 kidney transplant recipients with invasive or disseminated Neoscytalidium infection

\begin{tabular}{|c|c|c|c|c|c|c|c|c|c|c|c|c|}
\hline Patient & Age & Sex & $\begin{array}{l}\text { Year of } \\
\text { diagnosis }\end{array}$ & Origin & $\begin{array}{l}\text { Time from } \\
\text { transplantation } \\
\text { (months) }\end{array}$ & $\begin{array}{l}\text { Immunosuppressive } \\
\text { regimensb }\end{array}$ & $\begin{array}{l}\text { Type/ } \\
\text { Localization }\end{array}$ & $\begin{array}{l}\text { Presence } \\
\text { of skin appendage } \\
\text { involvement }\end{array}$ & Identification & Treatment & & Outcome \\
\hline & & & & & & & & & & First line & Second line & \\
\hline 1 & 53 & Male & 2001 & $\begin{array}{l}\text { French } \\
\text { Guyana }\end{array}$ & 3 & $\begin{array}{l}\text { Mycophenolic acid } \\
(250 \mathrm{mg}) \text {, tacrolimus } \\
(6 \mathrm{mg}) \text { and prednisone } \\
(20 \mathrm{mg})\end{array}$ & $\begin{array}{l}\text { Deep } \\
\text { cutaneous/ } \\
\text { right leg }\end{array}$ & Nail & $\begin{array}{l}\text { Neoscytalidium } \\
\text { sp }\end{array}$ & $\begin{array}{l}\text { Itraconazole + } \\
\text { surgical } \\
\text { resection }\end{array}$ & $\begin{array}{l}\text { Local } \\
\text { amphotericin } \\
\text { B added }\end{array}$ & $\begin{array}{l}\text { Surgery first failed, then } \\
\text { oral and local treatment } \\
\text { succeeded after more } \\
\text { than } 4 \text { months }\end{array}$ \\
\hline 2 & 64 & Female & 2002 & $\begin{array}{l}\text { Ivory } \\
\text { Coast }\end{array}$ & 134 & $\begin{array}{l}\text { Cyclosporine }(100 \mathrm{mg}) \\
\text { and prednisolone } \\
(10 \mathrm{mg})\end{array}$ & $\begin{array}{l}\text { Deep } \\
\text { cutaneous/ } \\
\text { left foot }\end{array}$ & $\begin{array}{l}\text { Right foot } \\
\text { (sole and nail), }\end{array}$ & $\begin{array}{l}\text { Neoscytalidium } \\
\text { hyalinum }\end{array}$ & $\begin{array}{l}\text { General (rapidly } \\
\text { discontinued) } \\
\text { and local } \\
\text { terbinafine, } \\
1 \text { year }\end{array}$ & & $\begin{array}{l}\text { Clinical success, but } \\
\text { samples positive } 1 \text { year } \\
\text { after treatment }\end{array}$ \\
\hline 3 & 52 & Male & 2007 & Mauritania & 105 & $\begin{array}{l}\text { Mycophenolic acid } \\
(1500 \mathrm{mg}) \text {, tacrolimus } \\
(3 \mathrm{mg}) \text { and prednisone } \\
\text { (10 mg). }\end{array}$ & $\begin{array}{l}\text { Deep } \\
\text { cutaneous/ } \\
\text { right ankle }\end{array}$ & & $\begin{array}{l}\text { Neoscytalidium } \\
\text { dimidiatum }\end{array}$ & $\begin{array}{l}\text { Surgical } \\
\text { resection only }\end{array}$ & & Surgery succeeded \\
\hline 4 & 59 & Male & 2011 & Cameroun & 8 & $\begin{array}{l}\text { Mycophenolic acid } \\
(1000 \mathrm{mg}) \text {, tacrolimus } \\
(30 \mathrm{mg}) \text {, and prednisone } \\
(7.5 \mathrm{mg})\end{array}$ & $\begin{array}{l}\text { Disseminated: } \\
\text { right leg and } \\
\text { foot }\end{array}$ & $\begin{array}{l}\text { Nail sample } \\
(2006)\end{array}$ & $\begin{array}{l}\text { Neoscytalidium } \\
\text { dimidiatum }\end{array}$ & $\begin{array}{l}\text { Voriconazole } \\
200 \mathrm{mg} \text { bid }\end{array}$ & $\begin{array}{l}\text { Local } \\
\text { ketoconazole } \\
\text { added }\end{array}$ & $\begin{array}{l}\text { Resolved in } 3 \text { months, } \\
\text { treatment } 5 \text { months. }\end{array}$ \\
\hline 5 & 49 & Male & 2011 & $\begin{array}{l}\text { Congo } \\
\text { Brazzaville }\end{array}$ & 15 & $\begin{array}{l}\text { Azathioprine }(50 \mathrm{mg}) \text {, } \\
\text { tacrolimus }(20 \mathrm{mg}) \text { and } \\
\text { prednisone }(15 \mathrm{mg})\end{array}$ & $\begin{array}{l}\text { Disseminated: } \\
\text { cutaneous/sinal } \\
\text { and pulmonary }\end{array}$ & & $\begin{array}{l}\text { Neoscytalidium } \\
\text { dimidiatum }\end{array}$ & $\begin{array}{l}\text { Voriconazole } \\
200 \text { mg bid }\end{array}$ & & Resolved in 1 year \\
\hline
\end{tabular}

${ }^{\mathrm{a}}$ For patients who underwent 2 transplantations, the time is the interval between diagnosis and the date of the second transplantation

${ }^{\mathrm{b}}$ Immunosuppressive regimen at the time of diagnosis; dosages are per day 
right ankle. A culture of the biopsy of this lesion grew $N$. dimidiatum. The lesion was resected successfully and no relapse was observed.

\section{Case 4}

The fourth patient was a 59-year-old male originated from Cameroon admitted to the hospital in October 2011 for the exploration of two cutaneous lesions. He had undergone renal transplantation in 1992 for end stage renal disease of undetermined origin. He was receiving a second renal graft in February 2011. At admission, his treatment consisted of tacrolimus (15 mg twice daily), mycophenolate mofetil (500 mg twice daily) and prednisone (7.5 mg daily). One lesion in the right pretibial region and one ulcerative lesion on the dorsal surface of the fifth toe of the right foot measuring $1 \times 2 \mathrm{~cm}$ were discovered during the dermatological examination (Fig. 1). These lesions had appeared 3 months earlier and grown progressively. Cultures of the lesions revealed $N$. dimidiatum. Histology of both lesions showed a granulomatous inflammation reaching the dermis. The diagnosis was thus a disseminated $N$. dimidiatum fungal infection with cutaneous involvement. Interestingly, $N$. dimidiatum had been previously identified on toenail samples in 2006. The patient was treated with voriconazole, $200 \mathrm{mg}$ twice daily. The lesions regressed and remaining lesions were surgically excised and local treatment with topical ketoconazole applications under gauze was added. The lesions completely disappeared 3 months after the diagnosis and voriconazole was stopped after 5 months. No relapse occurred.

\section{Case 5}

The fifth patient was a 49-year-old male from the Republic of Congo. He was admitted to the hospital in May 2011 for multiple active cutaneous lesions. His medical history included a renal transplantation in February 2010 for a nephropathy of unknown origin. The

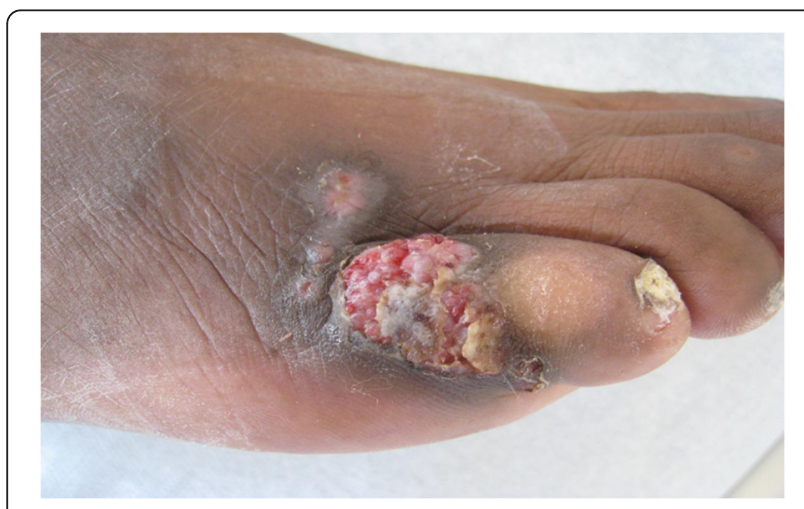

Fig. 1 Lesion due to Neoscytalidium dimidiatum in a kidney transplant recipient lesions consisted of large painless ulcerated tumors on the left elbow, an infiltrated nodule on the back and an ulceration on the right leg (Fig. 2). Direct examination of samples from these lesions showed many fungal elements. Culturing led to the identification of $N$. dimidiatum at all sites. For that isolate, the macro/microscopic examination result was confirmed by internal transcribed spacer (ITS) sequencing using the following primers ITS1 5' -TCCGTAGGTGAACCTGCGG-3' and ITS4 5'-TCCTCCGCTTATTGATATGC-3'. Moreover, bronchoalveolar lavage and nasal septum biopsy cultures were also positive, thus illustrating a disseminated form of $N$. dimidiatum. Blood cultures remained negative. Minimal inhibitory concentrations as determined by Etest (bioMérieux, Marcy l'Etoile, France) were: $0.032 \mu \mathrm{g} / \mu \mathrm{L}$ for voriconazole, $0.5 \mu \mathrm{g} / \mu \mathrm{L}$ for posaconazole, $12 \mu \mathrm{g} / \mu \mathrm{L}$ for fluconazole, and $0.38 \mu \mathrm{g} / \mu \mathrm{L}$ for amphotericin B. The minimal effective concentration was $0.064 \mu \mathrm{g} / \mu \mathrm{L}$ for both caspofungin and micafungin. Treatment with voriconazole was initiated and immunosuppression was reduced to a bitherapy with prednisolone and tacrolimus. Evolution was favorable with complete regression of the lesions (Fig. 2) within 12 months. The patient was then lost to follow-up for a year, but in the following year he was received for a medical visit during which the disappearance of lesions with residual scars and negative cultures were observed.

\section{Neoscytalidium superficial infections}

In our hospital, over 2 years (January 1, 2010 to December 31, 2011), 4466 cutaneous or skin appendage (i.e. nail, skin or hair samples) were obtained from 2577 patients for fungal confirmation/identification, resulting in 1540 (977 patients) positive cultures. Among these latter, Neoscytalidium spp. were identified in 77 isolates (5\% of all positive samples) from 42 patients representing $4.3 \%$ of all patients with positive fungal culture. Precisely, $73.8 \%$ of these Neoscytalidium patients $(n=31)$ had $N$. dimidiatum and $26.2 \%(n=11) N$. hyalinum.

\section{Discussion}

In endemic regions, Neoscytalidium spp. are an important cause of onychomycosis, accounting for $9 \%$ of cases in Nigeria, $24 \%$ in Gabon, and up to $56 \%$ in the West Indies [23]. A retrospective study on cases occurring between 1994 and 1999 in mainland France showed that Neoscytalidium spp. infections accounted for $3.6 \%$ of onychomycosis cases [3]. Similar results have been found in the United Kingdom where Neoscytalidium spp. were responsible for $3 \%$ of onychomycosis cases [24]. These cases are imported, involving migrants from endemic regions [3]. The epidemiological data concerning Neoscytalidium superficial infection obtained in our hospital over a 2-year analysis period (January 1, 2010 to 

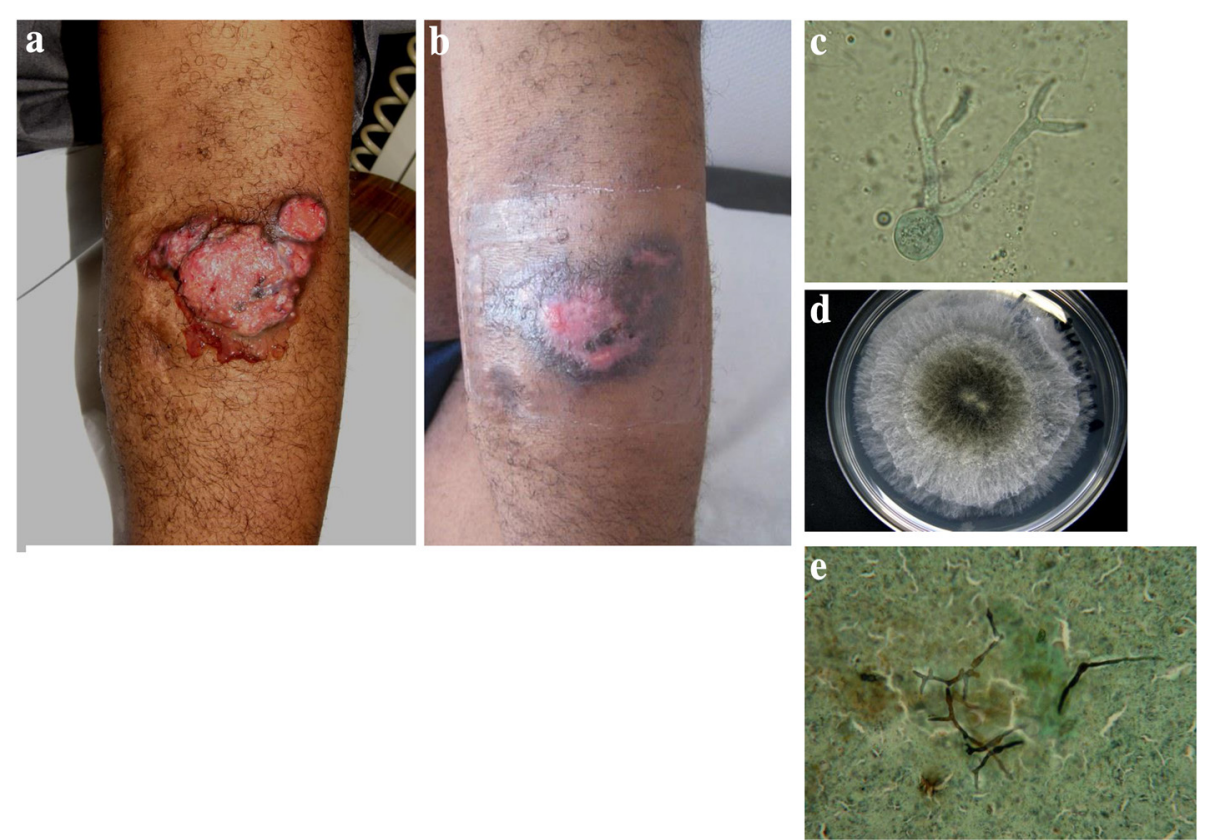

Fig. 2 Disseminated Neoscytalidium dimidiatum infection in a kidney transplant recipient. Lesion on the left elbow at presentation (2a) and after 2 months of voriconazole therapy (2b). Other localizations included the lungs, sinuses and right leg (2c and $2 \mathbf{e})$. Microscopic examination of the arm lesion showing hyphal fungal elements (2d). Photo of the 72-h culture from the arm lesion showing mold with a black center and white edges

December 31, 2011) were consistent with those of previous epidemiological studies performed in Paris and London $[25,26]$ with respectively 67 and $73 \%$ of cases of neoscytalidiosis due to Neoscytalidium dimidiatum.

Only a few cases of invasive/disseminated Neoscytalidium infections have been described. An aspect of interest for our case reports, although we only have five, is that they all occurred in renal transplant patients. In an article describing one case of invasive $N$. dimidiatum infection in an immunocompetent adult and reviewing 10 others cases of invasive Neoscytalidium infections with affection of deep organs, Elinav et al. reported that most of their invasive Neoscytalidium infections occurred in immunocompromised patients, including lung, renal or cardiac transplant recipients [11]. Additional aspects retrievable from the literature include other underlying conditions such as trauma, diabetes and cirrhosis. Neoscytalidium infections can occur in immunocompetent patients, with at least two cases reported. Neoscytalidium infections have been reported to manifest as central nervous system abscess, endophthalmitis, empyema, sinusitis and spondylodiscitis. Some authors have reported a poor prognosis with $50 \%$ mortality for these infections but did not outline attributable mortality. Interestingly, of the deaths reported in the literature, two occurred in renal transplant patients [11-21,27].

Deep localized subcutaneous infections (similar to what we report) are more frequently described in the literature. These lesions have been reported in immunocompromised patients using long-term corticosteroids [16, 28], in a cardiac transplant recipient [29], in renal transplant recipients $[7,30]$, in a discoid lupus erythematosus patient [31], in a case of liver cirrhosis [32], in a granulocytopenic child [21] and in a T-cell deficient patient [33]. Most of them were treated with a combination of systemic and local antifungal agents. Skin is more generally a frequent site of phaeohyphomycosis, up to $26 \%$ in one review [34].

All of our patients were from the Caribbean overseas departments of France or from Africa and frequently returned to their places of origin where Neoscytalidium spp. are endemic [1]. Interestingly, one patient had a concomitant onychomycosis due to Neoscytalidium (patient 1) and another had been diagnosed for onychomycosis due to Neoscytalidium 5 years earlier (patient 4). Patient 3 had similar lesions at an interval of 6 years. Unfortunately, the fungus in the earlier lesion was not identified (culture remained sterile), which reveals the difficulties in diagnosing these infections. These observations suggest that patients with "dermatophyte-like" superficial infections with mild or no symptoms are at risk of developing a deep cutaneous infection after many years of immunodepression. Therefore, in patients who are particularly at risk, i.e. immunocompromised and originated from tropical zones, checking and even sampling for onychomycosis should be done.

We note that our cases occurred exclusively in renal transplant recipients despite the fact that our institution also performs heart, liver and hematopoietic stem cell 
transplantations. We do not have a specific explanation for this observation but it is likely that the limited number of cases may play a role and moreover impair a relevant statistical analysis. We note too that all our patients were severely immunocompromised and had been receiving immunosuppressive drugs for a very long time. Two had undergone renal transplantation twice. Furthermore, opportunistic infections (i.e. Kaposi's sarcoma, Pneumocystis jiroveci pneumonia and toxoplasmosis) were diagnosed in three of our patients, reflecting the impairment of their immune function.

We encountered diagnostic difficulties in two patients with Kaposi's sarcoma. In one, it was difficult to determine if the concerned lesions were due to secondary infection of Kaposi's sarcoma lesions or primitive fungal infections, especially on the patient's black skin. A link between Kaposi's sarcoma and Scytalidium infection has been reported in HIV-infected patients [35]. This might suggest either that Kaposi's lesions favor fungal infection or that fungal lesions may be misidentified and necessitate multiple biopsies and cultures for various infectious analyses.

Neoscytalidium spp. infections have no standardized treatment [1]. The mold is frequently resistant in vivo despite in vitro susceptibility tests showing low minimal inhibitory concentrations [MICs] [36-38]. In superficial infections, oral and topical treatments classically used against dermatophytes [griseofulvin, ketoconazole, itraconazole] are often ineffective with Neoscytalidium spp., possible due to melanin production [7, 36]. Successful eradication of mycosis has been obtained with systemic use of azoles [voriconazole and itraconazole] or with amphotericin B. However, in most cases, healing is protracted and combinations of drugs are often necessary [39].

In disseminated infections, many treatments have been used with various outcomes. Elinav et al. reported that four patients died and one was cured with amphotericin $\mathrm{B}$, three died and one was cured with voriconazole, one died with posaconazole, and one was cured with ketoconazole [11].

In our series, all patients were cured. The difficulties in eradicating this infection and the absence of standardized care are reflected in the variety of treatments used for our patients. Importantly, patient five, who presented a disseminated infection and large cutaneous lesions, had a very good response under voriconazole only and no need for surgical resection of the lesions. It should be noted that the immunosuppressive regimen of this patient was downscaled, which might have enhanced his cure. In the other cases, the combination of surgical excision and medical treatment of lesions appeared to be a good option, as described in the literature, but we obtained successful outcomes as well with only oral voriconazole monotherapy in one patient and with only surgical excision for another.

\section{Conclusion}

Deep cutaneous infections due to the black exotic mold Neoscytalidium spp. are rare events occurring primarily in immunocompromised patients such as the renal transplant recipients described here. Dissemination can occur and threaten prognosis. Systemic azole therapy appears to be of interest and may prevent the need for an immediate surgical intervention in some cases, although for others, surgery remains the most appropriate solution.

\section{Consent}

All patients provided written informed consent for the publication of the case report and any accompanying images. A copy of the written consent is available for review by the Editor of this journal.

\section{Abbreviations \\ CT: Computed tomography; EORTC/MSG: European Organization for Research and Treatment of Cancer/Mycoses Study Group; ITS: Internal transcribed spacer; MICs: Minimal inhibitory concentrations.}

\section{Competing interests}

All authors declare that they have no conflict.

\section{Authors' contributions}

SG drafted the manuscript. JT and SB participated in the design of the study, and writing of the paper. IM carried out the mycological analysis and isolates identification. $N A, C F, D M, A D$ and $B B$ participated in the design of the study, and writing of the paper. AF conceived of the study, and participated in its design and coordination and wrote the manuscript. All authors read and approved the final manuscript.

\section{Funding}

This work was supported by internal funding.

\section{Highlights}

Neoscytalidium are black fungi with a worldwide distribution. They can cause invasive infections in renal transplant recipients.

There is no recommendation for a standardized treatment against Neoscytalidium spp.

In one case, medical treatment alone was sufficient for treating Neoscytalidium disseminated infection.

Neoscytalidium lesions can be confused with Kaposi's sarcoma.

\section{Author details}

${ }^{1}$ AP-HP, Groupe hospitalier La Pitié-Salpêtrière, Service de Parasitologie Mycologie, F-75013 Paris, France. ²Département d'urologie, néphrologie et transplantation, AP-HP, Groupe hospitalier Pitié-Salpêtrière, F-75013 Paris, France. ${ }^{3}$ Sorbonne Universités, UPMC Univ Paris 06, F-75005 Paris, France. ${ }^{4}$ AP-HP, Groupe hospitalier Pitié-Salpêtrière, Unité fonctionnelle de Dermatologie F-75013, Université Paris Sorbonne-UPMC, Paris, France. ${ }^{5}$ Centre d'Immunologie et des Maladies Infectieuses, CIMI-Paris, F-75013 Paris, France.

Received: 20 July 2015 Accepted: 21 October 2015

Published online: 19 November 2015

\section{References}

1. Machouart M, Menir P, Helenon R, Quist D, Desbois N. Scytalidium and scytalidiosis: What's new in 2012? J Med Mycol. 2013;23:40-6. 
2. Xavier AP, de Oliveira JC, Ribeiro VL, Souza MA. Epidemiological aspects of patients with ungual and cutaneous lesions caused by Scytalidium spp. An Bras Dermatol. 2010;85:805-10.

3. Lacroix C, Kac G, Dubertret L, Morel P, Derouin F, de Chauvin MF. Scytalidiosis in Paris, France. J Am Acad Dermatol. 2003;48:852-6.

4. Cursi ÍB, Freitas LB, Neves Mde LPF, Silva IC. Onycomychosis due to Scytalidium spp.: a clinical and epidemiologic study at a University Hospital in Rio de Janeiro, Brazil. An Bras Dermatol. 2011;86:689-93.

5. De Hoog GS. Atlas of clinical fungi. 2nd ed. Utrecht: Centraalbureau voor Schimmelcultures; 2004.

6. Lacaz CS, Pereira AD, Heins-Vaccari EM, Cucé LC, Benatti C, Nunes RS, et al. Onychomycosis caused by Scytalidium dimidiatum. Report of two cases. Review of the taxonomy of the synanamorph and anamorph forms of this coelomycete. Rev Inst Med Trop Sao Paulo. 1999;41:318-23.

7. Morris-Jones R, Youngchim S, Hextall JM, Gomez BL, Morris-Jones SD, Hay $\mathrm{RJ}$, et al. Scytalidium dimidiatum causing recalcitrant subcutaneous lesions produces melanin. J Clin Microbiol. 2004:42:3789-94.

8. Nattrass RM. A new species of Hendersonula (H. Toruloidea) on deciduous trees in Egypt. Br Mycol Soc Trans. 1933;18:189.

9. Gentles JC, Evans EG. Infection of the feet and nails with Hendersonula totuloidea. Sabouraudia. 1970;8:72.

10. Campbell CK, Mulder JL. Skin and nail infection by Scytalidium hyalinum sp. nov. Sabouraudia. 1977;15:161.

11. Elinav H, Izhar U, Benenson S, Admon D, Hidalgo-Grass C, Polacheck I, et al. Invasive Scytalidium dimidiatum infection in an immunocompetent adult. J Clin Microbiol. 2009;47:1259-63.

12. Khan ZU, Ahmad S, Joseph L, Chandy R. Cutaneous phaeohyphomycosis due to Neoscytalidium dimidiatum: first case report from Kuwait. J Med Mycol. 2009;19:138-42.

13. Sadeghi Tari A, Mardani M, Rahnavardi M, Asadi Amoli F, Abedinifar Z. Post-traumatic fatal Nattrassia mangiferae orbital infection. Int Ophthalmol. 2007:26:247-50.

14. Willinger B, Kopetzky G, Harm F, Apfalter P, Makristathis A, Berer A, et al. Disseminated infection with Nattrassia mangiferae in an immunosuppressed patient. J Clin Microbiol. 2004;42:478-80

15. Dunn JJ, Wolfe MJ, Trachtenberg J, Kriesel JD, Orlandi RR, Carroll KC. Invasive fungal sinusitis caused by Scytalidium dimidiatum in a lung transplant recipient. J Clin Microbiol. 2003;41:5817-9.

16. Moutran R, Maatouk R, Wehbé J, Abadjian G, Obeid G. Subcutaneous infection spread by Scytalidium (Neoscytalidium) dimidiatum. An Dermatol et de Vénéréol. 2012;139:204-8.

17. Mani RS, Chickabasaviah YT, Nagarathna S, Chandramuki A, Shivprakash MR, Vijayan J, et al. Cerebral phaeohyphomycosis caused by Scytalidium dimidiatum: a case report from India. Med Mycol. 2008;46(7):705-11.

18. Geramishoar M, Zomorodian K, Zaini F, Saadat F, Tarazooie B, Norouzi M, et al. First case of cerebral phaeohyphomycosis caused by Nattrassia mangiferae in Iran. Jpn J Infect Dis. 2004;57(6):285-6.

19. Gumbo T, Mkanganwi N, Robertson VJ, Masvaire P. Case report. Nattrassia mangiferae endophthalmitis. Mycoses. 2002;45:118-9.

20. Al-Rajhi AA, Awad AH, al-Hedaithy SS, Forster RK, Caldwell KC. Scytalidium dimidiatum fungal endophthalmitis. Br J Ophthalmol. 1993;77:388-90.

21. Benne CA, Neeleman C, Bruin M, de Hoog GS, Fleer A. Disseminating infection with Scytalidium dimidiatum in a granulocytopenic child. Eur J Clin Microbiol Infect Dis. 1993;12:118-21.

22. De Pauw B, Walsh TJ, Donnelly JP, Stevens DA, Edwards JE, Calandra T, et al. Revised definitions of invasive fungal disease from the European Organization for Research and Treatment of Cancer/Invasive Fungal Infections Cooperative Group and the National Institute of Allergy and Infectious Diseases Mycoses Study Group (EORTC/MSG) Consensus Group. Clin Infect Dis. 2008:46:1813-21.

23. Belloeuf $L$, Boisseau-Garsaud AM, Saint-Cyr I, Desbois N, Hélénon R, Quénéhervé C, et al. Nail disease due to Scytalidium in Martinique (French West Indies). Ann Dermatol Venereol. 2004;131(3):245-9.

24. Midgley G, Moore MK, Cook JC, Phan QG. Mycology of nail disorders. J Am Acad Dermatol. 1994;31(3 Pt 2):S68-74.

25. Badillet G, de Bièvre C, Gueho E. The Hendersunola genus. In: Opprtunistic Fungus. Clinical and Biological Atlas. Tome II : filamentous fungi. Paris; 1992. [in French].

26. Moore MK. Hendersonula toruloidea and Scytatalidium hyalinum infections in London, England. J Med Vet Mycol. 1986;24:219-30.
27. Tan DH, Sigler L, Gibas CF, Fong IW. Disseminated fungal infection in a renal transplant recipient involving Macrophomina phaseolina and Scytalidium dimidiatum: case report and review of taxonomic changes among medically important members of the Botryosphaeriaceae. Med Mycol. 2008;46:285-92.

28. Sigler L, Summerbell RC, Poole L, Wieden M, Sutton DA, Rinaldi MG, et al. Invasive Nattrassia mangiferae infections: case report, literature review, and therapeutic and taxonomic appraisal. J Clin Microbiol. 1997;35:433-40.

29. Sriaroon C, Vincent AL, Silapunt S, Chandler A, Houston SH, Greene JN. Transplantation. Successful treatment of subcutaneous Scytalidium hyalinum infection with voriconazole and topical terbinafine in a cardiac transplant patient. Transplantation. 2008;85(5):780-2.

30. Rockett MS, Gentile SC, Zygmunt KH, Gudas CJ. Subcutaneous phaeohypomycosis caused by Scytalidium dimidiatum in the foot of an immunosuppressed host. J Foot Ankle Surg. 1996;35(4):350-4.

31. Dhindsa MK, Naisdu J, Singh SM. A case of subcutaneous infection in a patient with discoid lupus erythematosus caused by Scytalidium synanamorph of Nattrassia mangiferae, and its treatment. Med Mycol. 1998;36:425-7.

32. Zaatari GS, Reed R, Morewessel R. Subcutaneous hyphomycosis caused by Scytalidium hyalinum. Am J Clin Pathol. 1984;82(2):252-6.

33. Mariat F, Liautaud B, Liautaud M, Marill FG. Hendersonula toruloidea, causative agent of a fungal verrucous dermatitis observed in Algeria. Sabouraudia. 1978;16(2):133-40.

34. Revankar SG, Sutton DA, Rinaldi MG. Primary central nervous system phaeohyphomycosis: a review of 101 cases. Clin Infect Dis. 2004;38:206-16.

35. Marriott DJ, Wong KH, Aznar E, Harkness JL, Cooper DA, Muir D. Scytalidium dimidiatum and Lecythophora hoffmannii: unusual causes of fungal infections in a patient with AIDS. J Clin Microbiol. 1997;35:2949-52.

36. Madrid H, Ruíz-Cendoya M, Cano J, Stchigel A, Orofino R, Guarro J. Genotyping and in vitro antifungal susceptibility of Neoscytalidium dimidiatum isolates from different origins. Int J Antimicrob Agents. 2009:34:351-4.

37. Dunand J, Paugam A. In vitro study of susceptibility of Scytalidium spp strains to posaconazole. Pathol Biol. 2008:56:268-71 [in French].

38. Lacroix C, de Chauvin MF. In vitro activity of amphotericin B, itraconazole, voriconazole, posaconazole, caspofungin and terbinafine against Scytalidium dimidiatum and Scytalidium hyalinum clinical isolates. J Antimicrob Chemother. 2008;61:835-7.

39. Spriet I, Lambrecht C, Lagrou K, Verhamme B. Successful eradication of Scytalidium dimidiatum-induced ungual and cutaneous infection with voriconazole. Eur J Dermatol. 2012;22(2):197-9.

\section{Submit your next manuscript to BioMed Central and take full advantage of:}

- Convenient online submission

- Thorough peer review

- No space constraints or color figure charges

- Immediate publication on acceptance

- Inclusion in PubMed, CAS, Scopus and Google Scholar

- Research which is freely available for redistribution 